\title{
Press Release: United Nations Approves 2022 as the International Year of Glass
}

\author{
Alicia Durán* \\ Research Professor CSIC, President of the ICG, Chair of IYOG2022, Madrid, Spain \\ *e-mail:manager@iyog2022.org
}

DOI: $10.1134 / \mathrm{S} 1087659621060353$

The International Commission on Glass (ICG), the Community of Glass Associations (CGA) and ICOM-Glass are promoting 2022 as a United Nations International Year of Glass to underline its scientific, economic and cultural roles and celebrate several anniversaries. Glass supports many vital technologies, facilitates sustainability and a green world and enriches our lives, yet often goes unnoticed.

This exciting journey began in 2018. Support came from 1500 Universities and research centers, societies and associations, museums, artists, educators, manufacturers and companies in 79 countries on 5 continents. Having successfully negotiated the disruption caused by a pandemic, a draft Resolution outlining our ambitions was negotiated with the Missions of several UN countries during April and passed the silent process on 11th May. The formal resolution was agreed at the United Nations General Assembly on May 18, 2021. Heartfelt thanks go to the Spanish Mission at the UN, particularly the Spanish ambassador Agustín Santos Maraver and Ana Alonso, who led this process through the difficult twists and turns of diplomacy in stressful times.

My deepest thanks go to all who responded to our vision. I need to cite some special persons such as David Pye and John Parker, but do not forget the many experts and colleagues that collaborated to create splendid videos and documents justifying our project; they were always ready and overflowing with ideas and support.

Today begins the task of diffusion and coordination of thousands of activities across the planet: congresses and seminars, industrial fairs and glass schools will coexist with artistic exhibitions, books, social media, scientific, technical and general interest magazines. Event planning will rely on grass roots input and a net- work of volunteers; delegation will be indispensable. National organizations will focus on advertising, sharing best practice and providing a supportive environment. A Steering Committee, based on representatives who can coordinate effectively with national institutions, will promote the best ideas and multiply their impact.

The internet, underpinned by glass fibre cables, and viewed through glass screens will support communication. We are designing a framework to record, develop and share ideas across the glass world based on our web site (www.iyog2022.org) and a LinkedIn group International Year of Glass 2022 exists.

Currently agreed are an Opening Conference in Geneva, an ICG Congress in Berlin, the Glass Expo in China with satellite events, plus Art/History Congresses in Egypt, the US and Europe. Dedicated issues of international journals will be printed, exhibitions are planned in museums, public and private glass collections, and educational materials are being prepared for universal dissemination.

The Spanish Research Council, CSIC, is committed to publishing a celebratory book and organizing exhibitions on: (a) IYOG objectives and (b) creating a Circular Economy based on recycling and glass containers. English and Spanish versions of exhibition materials will be offered to all supporting countries with translation possible.

Another task is fundraising, particularly to finance the opening event in Geneva. A team is poised for action.

IYOG 2022 is a dream come true, one we scarcely dared to anticipate. We are moved by the joy of dreams fulfilled, prepared for challenges ahead and limited only by our imaginations. 